Article

\title{
Electropolymerisation of Aniline on AZ91 Magnesium Alloy: The Effect of Coating Electrolyte Corrosiveness
}

\author{
Asif Baloch and M. Bobby Kannan * \\ Discipline of Chemical Engineering, College of Science and Engineering, James Cook University, \\ Townsville 4811, Australia \\ * Correspondence: bobby.mathan@jcu.edu.au; Tel.: +61-7-4781-5080
}

Received: 22 September 2017; Accepted: 27 November 2017; Published: 29 November 2017

\begin{abstract}
In this study, polyaniline was coated on AZ91 magnesium alloy using an electropolymerisation technique, and the effect of corrosiveness of the coating electrolytes on the polymerisation and the coating performance were evaluated. Two electrolytes, i.e., aniline + sodium salicylate (PASS) and aniline + potassium hydroxide (PAPH), with different corrosiveness, were used for polyaniline coating on AZ91 magnesium alloy. Potentiodynamic polarisation results suggested that salicylic acid $\left(\mathrm{C}_{7} \mathrm{H}_{5} \mathrm{NaO}_{3}\right)$ was more corrosive for the alloy than potassium hydroxide $(\mathrm{KOH})$, which can be attributed to the difference in the $\mathrm{pH}$ of the electrolytes. The PASS electrolyte coating formed on the alloy was relatively thick $(\sim 9 \mu \mathrm{m})$ and exhibited scattered pore-like morphology, whereas the PAPH electrolyte coating was thin $(\sim 3 \mu \mathrm{m})$ and uniform. Fourier Transform Infrared (FTIR) spectroscopy analysis revealed that the PASS electrolyte coating corresponds to polyaniline, whereas the PAPH electrolyte coating showed weak polyaniline bands. The corrosion protection performance of the coatings was evaluated in chloride-containing solution. The potentiodynamic polarisation results suggested that the corrosion rate of the alloy decreased significantly with the PASS electrolyte coating, whereas the PAPH electrolyte coating was detrimental. The degree of protection (DP) provided by the PASS electrolyte coating was $\sim 83 \%$. Post-corrosion analysis revealed higher corrosion attack in the PAPH electrolyte-coated alloy in comparison with the PASS electrolyte coated alloy. Thus, it can be concluded that the corrosiveness of the PASS coating electrolyte did not adversely affect the formation/performance of polyaniline on AZ91 magnesium alloy.
\end{abstract}

Keywords: magnesium alloy; polyaniline; corrosion

\section{Introduction}

Magnesium alloys are attractive materials for structural engineering applications due to their high-strength-to-weight ratio and formability [1-3]. However, the wide-spread use of magnesium alloys has been hindered due to their poor corrosion resistance [4-6]. Generally, magnesium alloys containing low impurities (iron and silicon) have acceptable atmospheric corrosion resistance, but the corrosion resistance deteriorates in the presence of chloride-containing environments $[4,5]$. Literature suggests that for AZ91 magnesium alloy, which is a popular magnesium alloy containing aluminium and zinc as alloying elements, the corrosion rate escalates with the increase in chloride-ion concentration, and the corrosion rate is also dependent on the $\mathrm{pH}$ of the electrolyte [5]. For example, in acidic solution $(\mathrm{pH}=2)$, the concentration of chloride ion does not affect the AZ91 magnesium alloy corrosion rate. However, in alkaline solution the chloride ion concentration influenced the corrosion rate of AZ91 magnesium alloy [5]. Feng et al. [7] reported that for AZ91 magnesium alloy, the thickness of magnesium hydroxide passive film increases with the increase in the electrolyte $\mathrm{pH}$ from 9 to 11 , 
and consequently decreases the corrosion rate. They also found that the hydrothermal treatment influenced the corrosion resistance of the alloy.

Many surface engineering/coating techniques such as electroplating, anodisation, micro-arc oxidation, chemical conversion, and polymer coatings have been studied to enhance the corrosion resistance of magnesium and magnesium-based alloys [7-13]. However, in recent years, conducting polymers have been gaining high interest for corrosion protection coating applications on engineering materials such as steel, copper, and magnesium due to their unique electrical properties [14-24]. Holness et al. [25] have elaborated the mechanism of the polyaniline inhibition of the corrosion on iron, which explains why conductive polymers are suitable for corrosion protection of metals. Further, these conducting polymers can be easily processed and are also economically viable for coating on metals. Polyaniline and polypyrrole are the most popular conducting polymers studied as coating materials for corrosion protection of metals. Iroh and Su [21] coated polypyrrole on a low carbon steel by an electrochemical method. They reported that the coating formed at a relatively low current density exhibited higher corrosion resistance as compared to that at a high current density. Similarly, Kazum, and Kannan [15] reported that electropolymerization of aniline on steel at $20 \mathrm{~mA} / \mathrm{cm}^{2}$ produced a polyaniline coating that performed better in a chloride-containing solution as compared to that formed at $30 \mathrm{~mA} / \mathrm{cm}^{2}$. They suggested that, at a higher applied current, the inevitable hydrogen evolution hindered the coating formation. However, Pawar et al. [22] reported that a uniform and strongly adherent polyaniline formed on mild steel using a cyclic voltammetry coating technique.

Electropolymerisation on a highly reactive metal such as magnesium could be challenging, since the metal may dissolve during the coating process if the electrolyte is corrosive. Literature suggests that salicylate solution is a widely used polymerisation agent for polyanline and polypyrrole formation on steel and copper $[15,16,22,23]$. Since salicylate solution is slightly acidic in nature, which can be corrosive for magnesium, some researchers have attempted to polymerise pyrrole [14] and aniline [24] on magnesium alloys in alkaline medium. Although the two studies showed successful polymerisation on magnesium alloys in alkaline medium, the corrosion protection properties were not investigated or inconclusive. It is well known that magnesium passivates in alkaline medium $[4,6]$, but to the authors' best knowledge the effect of such passivation on the polymerisation has not be studied. Hence, it is worthwhile to study the effect of the corrosiveness of the coating electrolyte on the polymerisation and the corrosion resistance performance of the polymer coating on a magnesium-based materials.

In this study, two electrolytes with different corrosiveness were used to electropolymerise aniline on a magnesium alloy. The coating performance was evaluated using the potentiodynamic polarisation technique in a chloride-containing solution.

\section{Materials and Methods}

The chemical composition of AZ91 magnesium alloy is given in Table 1. Electropolymerisation was carried out using a potentiostat (Model: VersaSTAT 3 PAR, Princeton Applied Research, Oak Ridge, TN, USA) and a typical three-electrode cell, i.e., alloy as the working electrode, silver/silver-chloride $(\mathrm{Ag} / \mathrm{AgCl})$ as the reference electrode, and graphite as the counter electrode. Prior to electropolymerisation, the alloy samples (sample size: $20 \mathrm{~mm} \times 20 \mathrm{~mm} \times 2 \mathrm{~mm}$ ) were initially ground with $\mathrm{SiC}$ papers (up to 2500 grit) followed by ultrasonic cleaning in acetone. A cyclic voltammetry technique (parameters: no. of cycles $=5$; vertex 1 and 2 potentials were $-1 \mathrm{~V}$ and $2.2 \mathrm{~V}$, respectively) was used for electropolymerization of aniline. Two different electrolytes were used for the coating, i.e., $0.3 \mathrm{M}$ aniline $+0.1 \mathrm{M}$ sodium salicylate $\left(\mathrm{C}_{7} \mathrm{H}_{5} \mathrm{NaO}_{3}\right)$ and $0.2 \mathrm{M}$ aniline $+0.25 \mathrm{M}$ potassium hydroxide $(\mathrm{KOH})$, and the coatings produced from the two electrolytes will hereafter be called as PASS and $\mathrm{PAPH}$ coatings, respectively. After electropolymerisation, the coated samples were placed in an oven at $80^{\circ} \mathrm{C}$ for $24 \mathrm{~h}$ to remove any residual electrolyte. An optical microscope (Model: Nikon Eclipse 50i POL, Nikon Instruments Inc., Tokyo, Japan) was used to examine the morphology of the coating. The coating thickness was measured using a coating thickness gauge (Model: Fisher DUALSCOPE 
MP0R, Fischer Technology Inc., Windsor, CT, USA), and the adhesion of the coating was measured using an adhesion tester (Model: Elcometer 106, Elcometer Limited, Manchester, UK).

Table 1. Chemical composition of AZ91 magnesium alloy (weight \%).

\begin{tabular}{ccccccc}
\hline Al & Zn & Mn & Fe & Cu & Si & Mg \\
\hline 8.81 & 0.79 & 0.21 & 0.003 & 0.003 & $<0.01$ & bal \\
\hline
\end{tabular}

Potentiodynamic polarisation technique was used to evaluate the performance of the coating in a chloride-containing solution $(0.5 \mathrm{~g} / \mathrm{L} \mathrm{NaCl})$. For comparison, the bare metal was also tested. In order to understand the effect of the polymerisation agents (potassium hydroxide and sodium salicylate) on the corrosion behaviour of the alloy, potentiodynamic polarisation experiments were also carried out in those electrolytes. The potentiodynamic polarisation experiments were carried out at $0.5 \mathrm{mV} / \mathrm{s}$ scan rate after exposing the sample in the electrolyte for $1 \mathrm{~h}$ to establish a relatively stable open circuit potential (OCP). To confirm reproducibility, all the experiments were conducted in triplicate. The degree of protection (DP) of the coating against corrosion was calculated using the below equation:

$$
\mathrm{DP}=\frac{\mathrm{i}_{\text {corr }}(\text { uncoated sample })-\mathrm{i}_{\text {corr }}(\text { coated sample })}{\mathrm{i}_{\text {corr }}(\text { uncoated sample })} \times 100
$$

\section{Results and Discussion}

Figure 1 shows the potentiodynamic polarisation curves of AZ91 magnesium alloy in potassium hydroxide and sodium salicylate electrolytes, and the corresponding electrochemical data are presented in Table 2. The $\mathrm{E}_{\text {corr }}$ of the alloy in potassium hydroxide was $\sim 275 \mathrm{mV}$ noble as compared to sodium salicylate. The cathodic and the anodic polarisation curves of the alloy in potassium hydroxide were towards the lower current side in comparison with sodium salicylate. Passivity in the anodic curve was evident in potassium hydroxide, whereas in salicylic acid the dissolution of the alloy was significant. As a result, the corrosion current $\left(\mathrm{i}_{\mathrm{corr}}\right)$ in sodium salicylate was close to two-orders of magnitude higher than in potassium hydroxide. The calculated corrosion rates for the alloy in sodium salicylate and potassium hydroxide were 34.96 and $0.46 \mathrm{mpy}$, respectively. The lower corrosion rate in potassium hydroxide electrolyte can be attributed to the formation of a protective film on the alloy surface in the alkaline medium ( $\mathrm{pH}=12.03)$. However, in the acidic medium of sodium salicylate solution ( $\mathrm{pH}=5.81$ ), the corrosion of the alloy was severe. The optical micrographs of the alloy after potentiodynamic polarisation experiments are shown in Figure 2. The alloy in potassium hydroxide showed very little corrosion, whereas in sodium salicylate the alloy exhibited high corrosion attack and also the secondary phase particles in the alloy were clearly revealed. It appears that the corrosion has started near the secondary phase particle regions, where the aluminium content was lean, and then propagated outwards.

Table 2. Electrochemical corrosion data of AZ91 magnesium alloy in two different electrolytes.

\begin{tabular}{ccc}
\hline Parameters & $\mathbf{0 . 1 0}$ M Sodium Salicylate & $\mathbf{0 . 2 5}$ M Potassium Hydroxide \\
\hline $\mathrm{E}_{\text {corr }}(\mathrm{mV})$ & $-1611 \pm 4.95$ & $-1335 \pm 11$ \\
$\mathrm{i}_{\text {corr }}\left(\mu \mathrm{A} / \mathrm{cm}^{2}\right)$ & $19.23 \pm 1.61$ & $0.2509 \pm 0.014$ \\
Corrosion Rate $(\mathrm{mpy})$ & 34.96 & 0.46 \\
$\mathrm{pH}$ & $5.81 \pm 0.16$ & $12.03 \pm 0.02$ \\
\hline
\end{tabular}




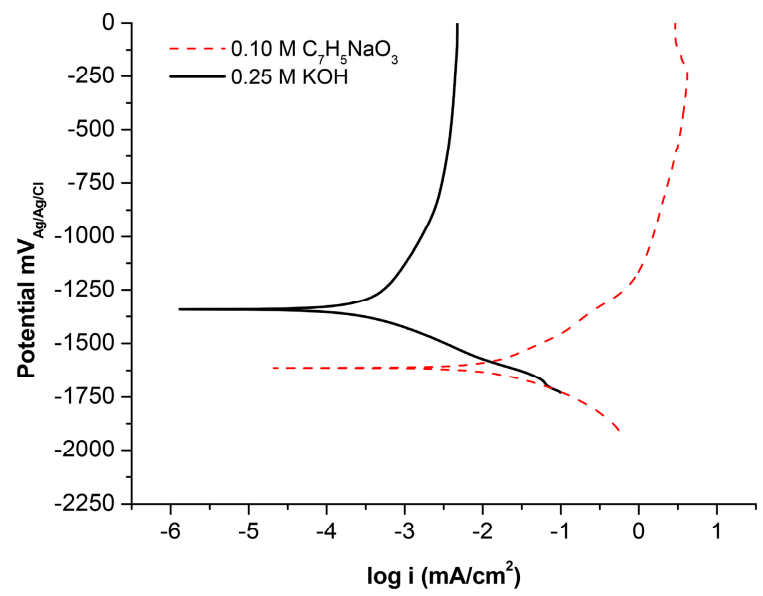

Figure 1. Potentiodynamic polarization curves of AZ91 magnesium alloy in sodium salicylate and potassium hydroxide solutions.
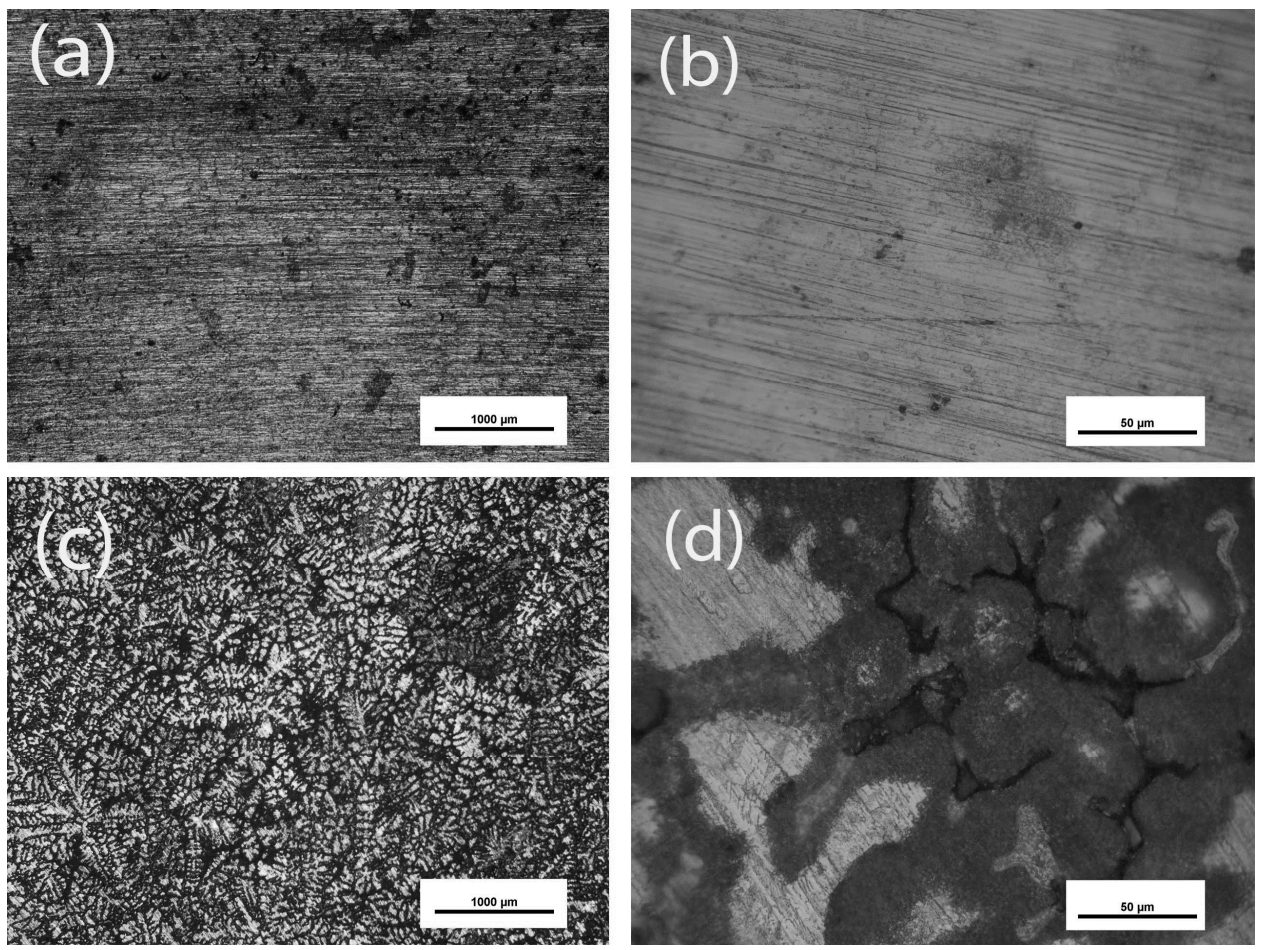

Figure 2. Optical micrographs of AZ91 magnesium alloy after potentiodynamic polarization experiments in $(\mathbf{a}, \mathbf{b}) 0.25 \mathrm{M}$ potassium hydroxide and (c,d) $0.1 \mathrm{M}$ sodium salicylate.

The cyclic voltametric curves for the alloy in the PASS and the PAPH electrolytes are shown in Figure 3. In PASS electrolyte, which contained an acidic sodium salicylate, the first-forward cycle showed a strong magnesium oxidation until $\sim 0.75 \mathrm{~V}$, and above that level oxidation of aniline started to occur. However, in the subsequent cycles, magnesium oxidation was insignificant due to the formation of polyaniline. The peak anodic current density at $2 \mathrm{~V}$ decreased with the increase in the number of cycles, confirming the growth of polyaniline coating. In the PAPH electrolyte, which contained a strong alkaline potassium hydroxide, there was little dissolution of magnesium during the first-forward cycle. Based on the anodic peak current density, it can be said that the oxidation of aniline in the PAPH electrolyte was significantly lower as compared to the PASS electrolyte. Further, it was noted that the peak current increased as the number of cycles increased in the PAPH electrolyte, which is in contrast 
to that observed in the PASS electrolyte. The anodic protective layer formed in the PAPH electrolyte has minimised the oxidation of aniline, and hence the formation of polyaniline was not significant.

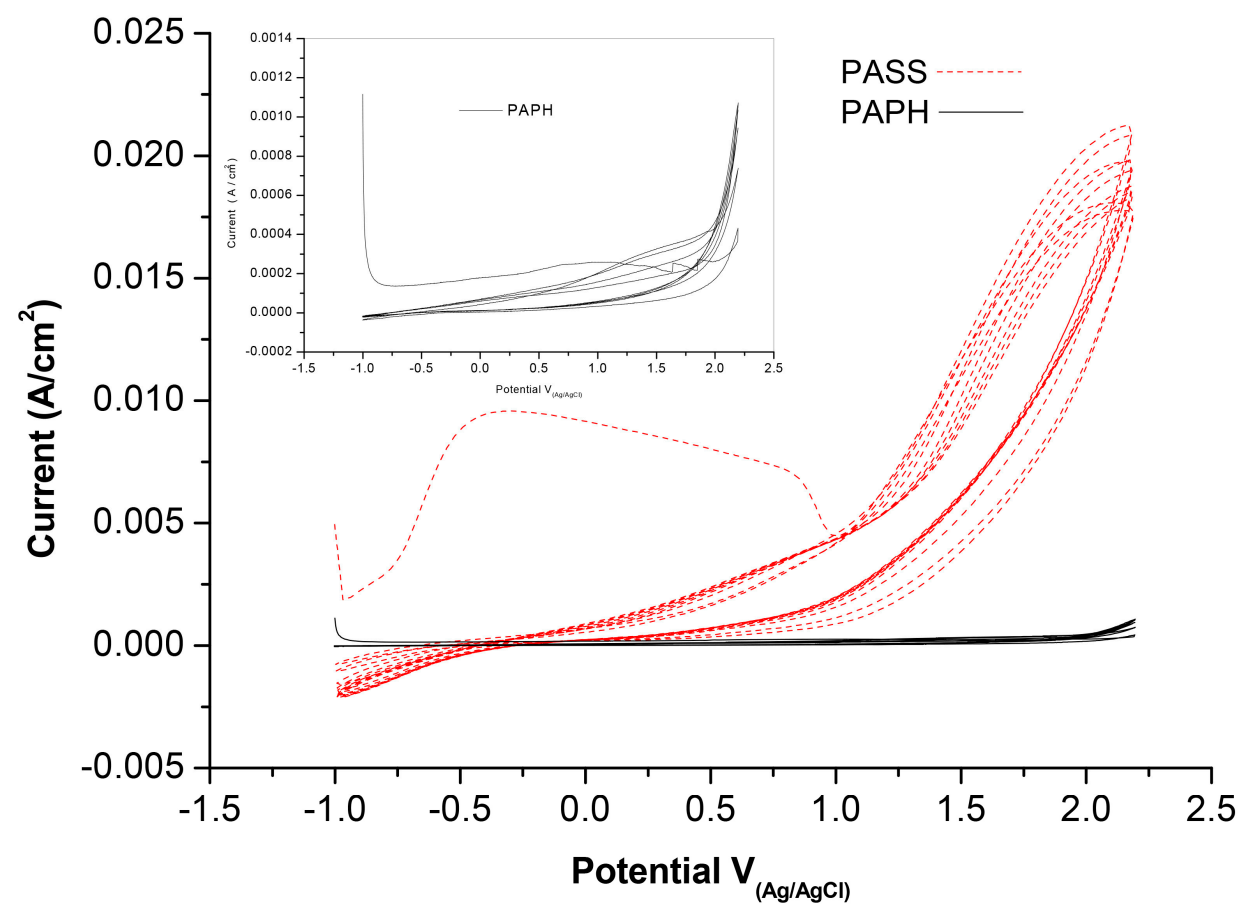

Figure 3. Cyclic voltammetry response of AZ91 magnesium alloy in PASS (aniline + sodium salicylate) and PAPH (aniline + potassium hydroxide) electrolytes.

Table 3 shows the coating thickness and adhesion strength results of the coatings on AZ91 magnesium alloy. The coating thickness measurements revealed a relatively thicker coating in the PASS electrolyte $(\sim 9 \mu \mathrm{m})$ as compared to the PAPH electrolyte $(\sim 3 \mu \mathrm{m})$. Visual observation of the PASS-coated alloy showed a dark bluish colour, but the PAPH coated alloy exhibited a light yellowish colour. The PASS coating adhesion strength was $\sim 2 \mathrm{~N} / \mathrm{mm}^{2}$, whereas the adhesion strength of PAPH coating was too low for measurement. The optical micrographs of the coatings are shown in Figure $4 \mathrm{a}-\mathrm{d}$. The PAPH coating was thin such that the alloy polishing scratches can be seen (Figure $4 \mathrm{~b}$ ). The PASS coating, however, exhibited scattered pore-like morphology and did not reveal any of the polishing scratches (Figure 4c). Similar pore-like morphology has been reported for polyaniline coating on steel, which has been attributed to the oxygen evolution reaction at high anodic potentials [15]. FTIR analysis of the coatings shown in Figure 5 confirmed that they are polyaniline, with PASS showing strong bands at $1000-1800 \mathrm{~cm}^{-1}$ [15], but they were slightly weaker with PAPH. Based on the colour and thickness measurement data, it can be suggested that the PAPH coating could be largely magnesium hydroxide with a thin polyaniline coating as a top layer.

Figure 6 shows the potentiodynamic polarisation curves of the PASS and the PAPH coated alloy in comparison with the bare alloy in chloride-containing solution. The corresponding electrochemical data are presented in Table 4 . The corrosion potential $\left(\mathrm{E}_{\text {corr }}\right)$ of the coated alloy samples was shifted towards the active direction as compared to the bare metal. The bare metal did not show any breakdown potential $\left(\mathrm{E}_{\mathrm{bd}}\right)$ in the anodic curve, but the coated alloy samples showed breakdown potentials. The $\mathrm{i}_{\mathrm{corr}}$ of the PASS-coated alloy was close to an order of magnitude lower than the bare metal. Interestingly, the PAPH-coated alloy showed higher $\mathrm{i}_{\text {corr }}$ as compared to the bare metal, but showed some passivity effect in the anodic polarisation curve. The corrosion rates of the bare metal, the PASS, and the PAPH-coated alloy samples were 2.02, 0.34, and $4.92 \mathrm{mpy}$, respectively. The degree of protection (DP) provided by the PASS coating was $\sim 83 \%$. The post-corrosion micrographs of the bare metal and the 
coated alloy samples are shown in Figure 7. The coatings minimised the localised corrosion attack of the alloy. The bare metal exhibited extensive localised corrosion through the sample (Figure 7a), whereas the PAPH-coated alloy revealed pockets of localised corrosion (Figure $7 \mathrm{~b}$ ). However, the PASS coating showed no recognisable region of corrosion attack. It should be noted that the uneven morphology of the PASS-coated alloy in Figure 7c is nothing but the coating morphology as seen in Figure 4c.

Table 3. Thickness and adhesion of the coatings formed on AZ91 magnesium alloy in two different electrolytes.

\begin{tabular}{ccc}
\hline Parameters & PASS Coating & PAPH Coating \\
\hline Thickness $(\mu \mathrm{m})$ & $8.75 \pm 0.24$ & $2.75 \pm 0.04$ \\
Adhesion $\left(\mathrm{N} / \mathrm{mm}^{2}\right)$ & $1.95 \pm 0.07$ & - \\
\hline
\end{tabular}
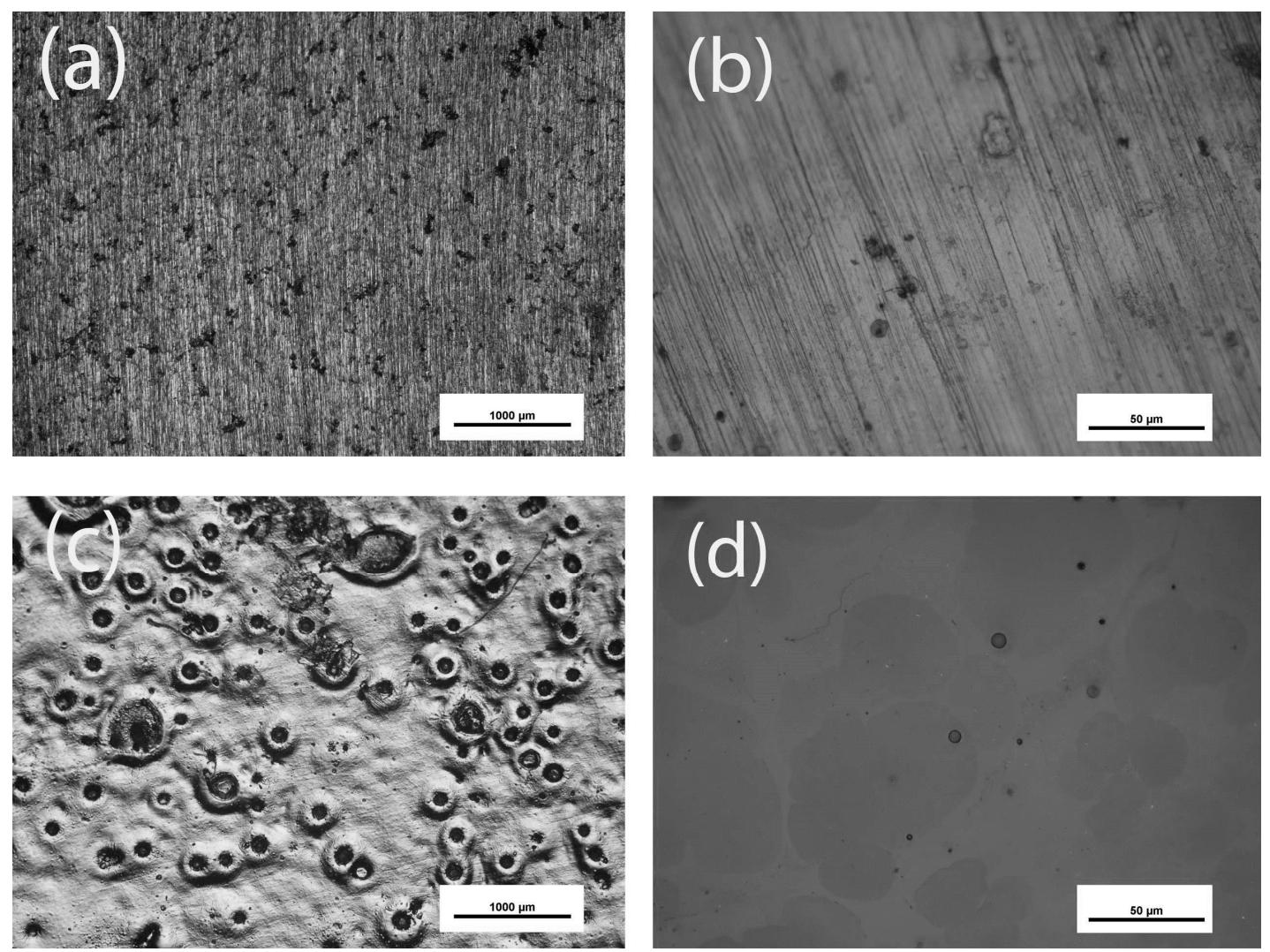

Figure 4. Optical micrographs of the coated AZ91 magnesium alloy: (a,b) PAPH coated, and (c,d) PASS coated.

Table 4. Electrochemical corrosion data of the bare metal and coated AZ91 magnesium alloy in chloride-containing solution.

\begin{tabular}{cccc}
\hline Parameters & Bare Metal & PASS Coated & PAPH Coated \\
\hline $\mathrm{E}_{\mathrm{corr}}(\mathrm{mV})$ & $-1296 \pm 63.23$ & $-1473 \pm 20.04$ & $-1428 \pm 12.73$ \\
$\mathrm{E}_{\mathrm{bd}}(\mathrm{mV})$ & - & $-1299 \pm 14.14$ & $1145 \pm 131.52$ \\
$\mathrm{i}_{\text {corr }}\left(\mu \mathrm{A} / \mathrm{cm}^{2}\right)$ & $1.03 \pm 0.28$ & $0.19 \pm 0.01$ & $2.71 \pm 0.33$ \\
Corrosion Rate $(\mathrm{mpy})$ & 2.02 & 0.34 & 4.92 \\
Degree of Protection $(\mathrm{DP})$ & - & $83.17 \%$ & - \\
\hline
\end{tabular}




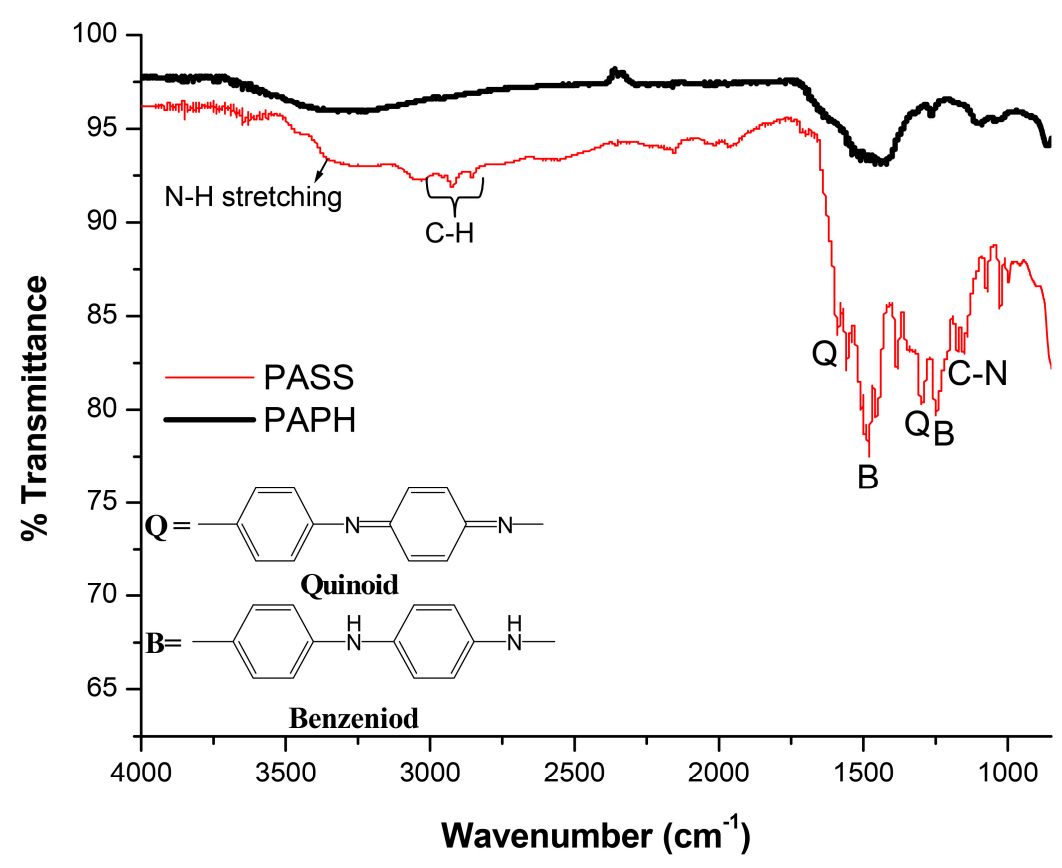

Figure 5. Fourier Transform Infrared (FTIR) analysis of PASS and PAPH coatings.

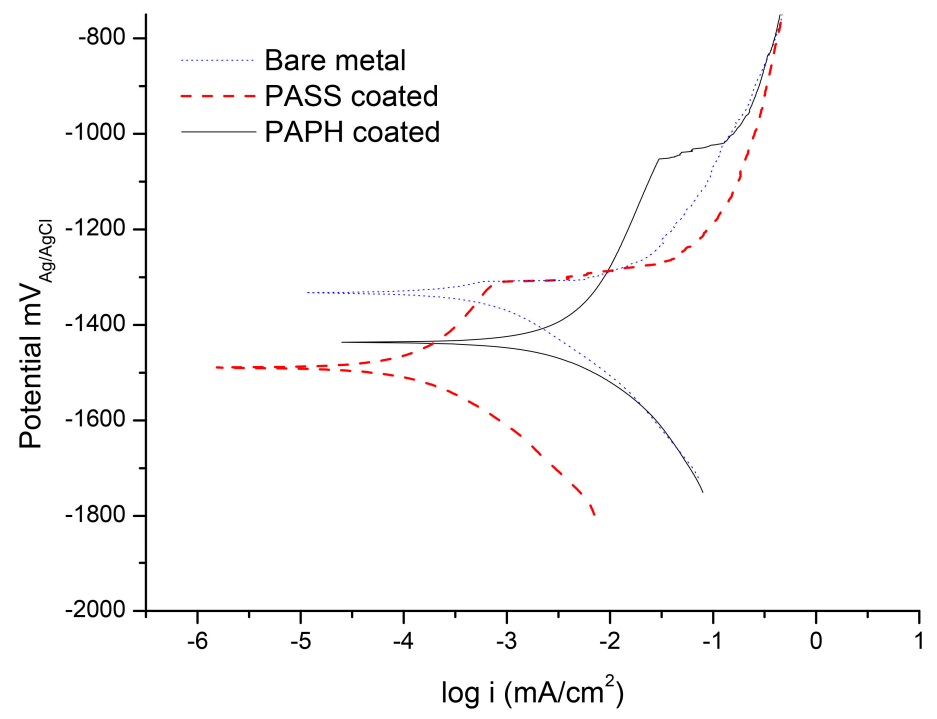

Figure 6. Potentiodynamic polarization curves of the bare metal and coated AZ91 magnesium alloy samples in chloride-containing solution.

Table 5 shows the $\mathrm{pH}$ of the coating electrolytes and the corrosion test solutions, i.e., before and after the potentiodynamic polarisation experiments. The PASS and PAPH coating electrolytes exhibited $\mathrm{pH}$ values of 6.52 and 12.08 , respectively. It can be noted that the corrosion test solution turned alkaline for the bare metal and the PAPH coated alloy after the potentiodynamic polarisation experiments, i.e., the $\mathrm{pH}$ change was from $\sim 6.5$ to $\sim 8.7$. This $\mathrm{pH}$ change indicates magnesium dissolution causing the increase in the $\mathrm{pH}$. However, the $\mathrm{pH}$ of the electrolyte of the PASS coated alloy did not change significantly after the corrosion test. 

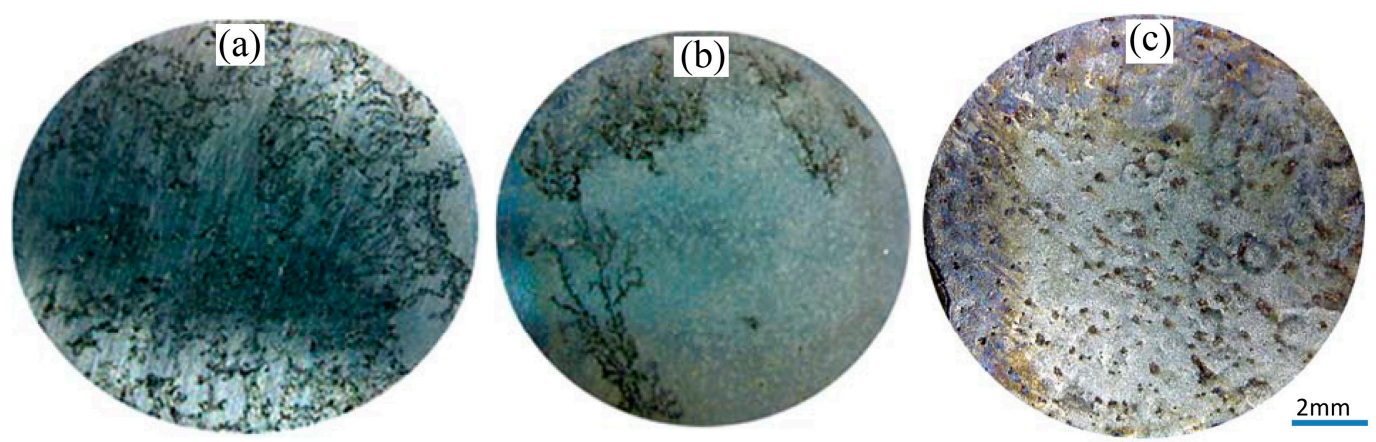

Figure 7. Post-corrosion macrographs of AZ91 magnesium alloy: (a) bare metal; (b) PAPH-coated; and (c) PASS-coated, after potentiodynamic polarization in chloride containing solution.

Table 5. The $\mathrm{pH}$ of the coating electrolytes and variations in the $\mathrm{pH}$ after potentiodynamic polarisation.

\begin{tabular}{cccc}
\hline \multirow{2}{*}{ Parameters } & \multicolumn{3}{c}{$\mathbf{p H}$} \\
\cline { 2 - 4 } & Coating Electrolyte & Before Corrosion & After Corrosion \\
\hline Bare Metal & & $6.56 \pm 0.26$ & $8.78 \pm 0.08$ \\
PASS Coated & $6.52 \pm 0.20$ & $6.67 \pm 0.08$ & $6.73 \pm 0.05$ \\
PAPH Coated & $12.08 \pm 0.02$ & $6.65 \pm 0.06$ & $8.76 \pm 0.02$ \\
\hline
\end{tabular}

The reaction mechanism of aniline electropolymerization is presented in Figure 8 [26]. The first step (I) of the polymerization process of aniline involves formation of aniline cation radicals by anodic oxidation on the electrode surface in an acidic solution. In the PASS electrolyte (Figure 3), a significant dissolution of the alloy can be observed at potentials starting from $-0.75 \mathrm{~V}$, which can be attributed to the relatively low $\mathrm{pH}$ (6.52) of the coating electrolyte. In fact, the low $\mathrm{pH}$ of the electrolyte catalyses the formation of aniline cation radicals. Cascalheira et al. $[16,23]$ reported that in electropolymerisation of pyrrole on copper metal, salicylate ions formed a copper salicylate complex on the metal surface, which facilitated polypyrrole formation. A similar mechanism is plausible for polyaniline formation on AZ91 magnesium alloy, i.e., magnesium salicylate complex promoting aniline polymerisation. The subsequent polymerisation reactions are coupling of the anilinium radicals and formation of a dimer (II), further oxidation (III), and chain propagation by coupling reactions (IV). As can be seen in Figure 3 for the PASS coating, the increase in the current density starting at $1.0 \mathrm{~V}$ in the first-sweep is due to the oxidation of aniline, and the reverse potential after reaching $2 \mathrm{~V}$ produces polyaniline. The decrease in the anodic peak current density from cycle 1 to 5 can be attributed to the growth of the polymer coating, which was evident from the optical micrographs (Figure 4) and FTIR spectra (Figure 5). In the case of the PAPH electrolyte (Figure 3), a strong alkaline medium (pH 12.08), the anodic current density in the first-sweep, was lower than in the PASS electrolyte, which suggests that the rate of magnesium dissolution decreased due to the immediate formation of a passive layer. The peak current increased as the number of cycles increased, suggesting slow formation of polyaniline. Thus, the study suggests that the passive layer formed on AZ91 magnesium alloy in the alkaline PAPH electrolyte has reduced the rate of aniline cation radical formation and consequently decreased the polymerisation process. A relatively corrosive PASS electrolyte, however, formed a thicker polyaniline coating on AZ91 magnesium alloy and exhibited significant corrosion protection. 


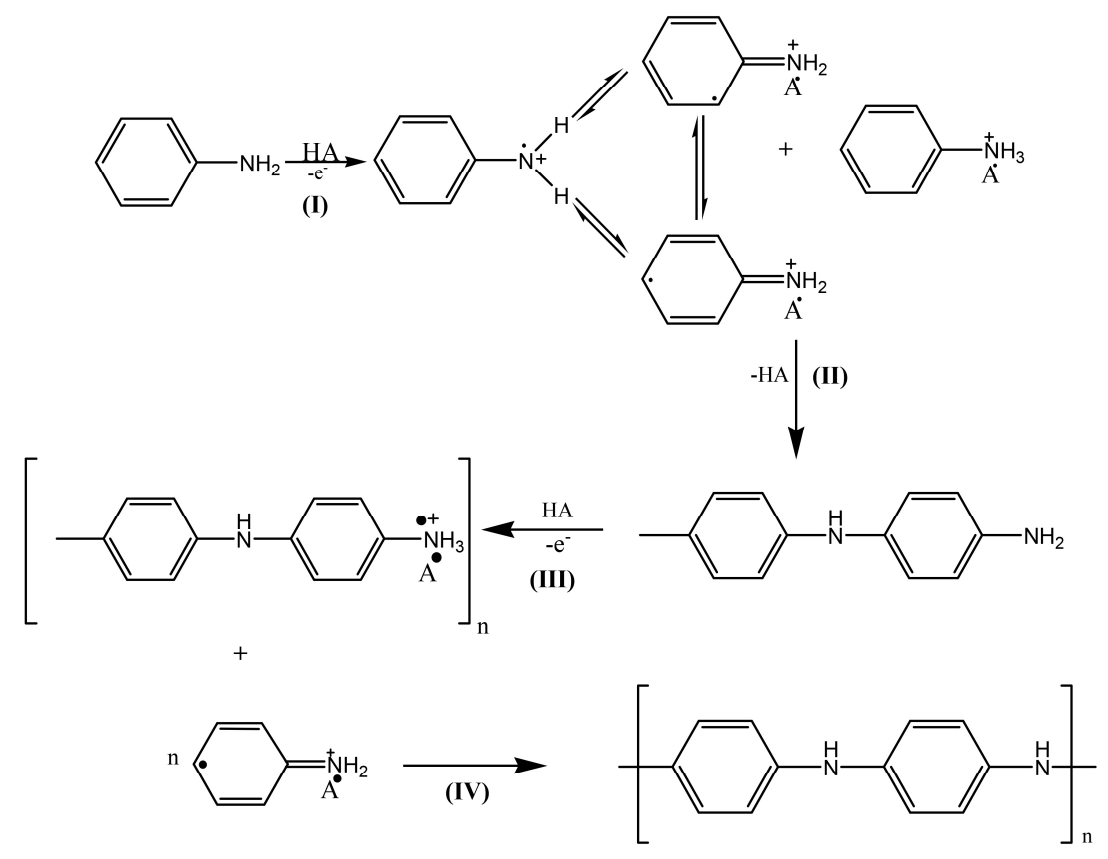

Figure 8. Electropolymerisation mechanism of aniline to polyaniline [26].

\section{Conclusions}

Polyaniline was coated on the AZ91 magnesium alloy using a cyclic voltammetry technique. The effect of coating electrolyte corrosiveness on the polymerisation and coating performance was investigated. Polyaniline coating in the aniline and sodium salicylate (PASS) electrolyte produced a better coating than in the aniline and potassium hydroxide (PAPH) electrolyte. The corrosion resistance provided by the PASS coating was significantly higher than the bare metal, but the PAPH coating was detrimental. Post-corrosion analysis revealed minimal corrosion attack in the PASS-coated alloy in comparison with the PAPH-coated alloy. The study suggests that the relatively high corrosiveness of the PASS coating electrolyte did not adversely affect the formation and performance of the polyanline coating on AZ91 magnesium alloy, whereas the passive film on the AZ91 magnesium alloy in the alkaline PAPH electrolyte lessened the polymerisation of aniline on the surface.

Acknowledgments: The authors would like to thank Mohamed Rahuma for the assistance in the preparation of the paper.

Author Contributions: M. Bobby Kannan conceived and designed the experiments; Asif Baloch performed the experiments; M. Bobby Kannan and Asif Baloch analyzed the data and wrote the paper.

Conflicts of Interest: The authors declare no conflict of interest.

\section{References}

1. Mordike, B.L.; Ebert, T. Magnesium properties, applications and potential. Mater. Sci. Eng. 2001, 302, $37-45$. [CrossRef]

2. Easton, M.; Beer, A.; Barnett, M.; Davies, C.; Dunlop, G.; Durandet, Y.; Blacket, S.; Hilditch, T.; Beggs, P. Magnesium alloy applications in automotive structures. J. Miner. Met. Mater. Soc. 2008, 60, 57-62. [CrossRef]

3. Kainer, K.U.; von Buch, F. The current state of technology and potential for further development of magnesium applications. In Magnesium-Alloys and Technology; Kainer, K.U., Ed.; Wiley-VCH Verlang GmbH \& Co. KGaA: Weinheim, Germany, 2004; pp. 1-12.

4. Song, G.; Atrens, A. Understanding magnesium corrosion-A frame work for improved alloy performance. Adv. Eng. Mater. 2003, 5, 837-858. [CrossRef] 
5. Ambat, R.; Aung, N.N.; Zhou, W. Studies on the influence of chloride ion and pH on the corrosion and electrochemical behaviour of AZ91D magnesium alloy. J. Appl. Electrochem. 2000, 30, 865-874. [CrossRef]

6. Song, G. Recent progress in corrosion and protection of magnesium alloys. Adv. Eng. Mater. 2005, 7, 563-586. [CrossRef]

7. Feng, J.; Chen, Y.; Liu, X.; Liu, T.; Zou, L.; Wang, Y.; Ren, Y.; Fan, Z.; Lv, Y.; Zhang, M. In-Situ hydrothermal crystallization $\mathrm{Mg}(\mathrm{OH})_{2}$ films on magnesium alloy AZ91 and their corrosion resistance properties. Mater. Chem. Phys. 2013, 143, 322-329. [CrossRef]

8. Zhang, Y.; Shao, Y.; Zhang, T.; Meng, G.; Wang, F. High corrosion protection of a polyaniline/organophilic montmorillonite coating for magnesium alloys. Prog. Org. Coat. 2013, 76, 804-811. [CrossRef]

9. Wu, L.; Zhao, J.; Xie, Y.; Yang, Z. Progress of electroplating and electroless plating on magnesium alloy. Trans. Nonfer. Met. Soc. China 2010, 20, 630-637. [CrossRef]

10. Li, L.; Cheng, Y.; Wang, H.; Zhang, Z. Anodization of AZ91 magnesium alloy in alkaline solution containing silicate and corrosion properties of anodized films. Trans. Nonferr. Met. Soc. China 2008, 18, 722-727. [CrossRef]

11. Guo, H.F.; An, M.Z.; Huo, H.B.; Xu, S.; Wu, L.J. Microstructure characteristic of ceramic coatings fabricated on magnesium alloys by micro-arc oxidation in alkaline silicate solutions. Appl. Surf. Sci. 2006, 252, 7911-7916. [CrossRef]

12. Sang, J.; Kang, Z.; Li, Y. Corrosion resistance of Mg-Mn-Ce magnesium alloy modified by polymer plating. Trans. Nonferr. Met. Soc. China 2008, 18, 374-379. [CrossRef]

13. Gu, C.D.; Yan, W.; Zhang, J.L.; Tu, J.P. Corrosion resistance of AZ31B magnesium alloy with a conversion coating produced from a choline chloride-urea based deep eutectic solvent. Corros. Sci. 2016, 106, 108-116. [CrossRef]

14. Jiang, Y.F.; Guo, X.W.; Wei, Y.H.; Zhai, C.Q.; Ding, W.J. Corrosion protection of polypyrrole electrodeposited on AZ91 magnesium alloys in alkaline solutions. Synth. Met. 2003, 139, 335-339. [CrossRef]

15. Kazum, O.; Kannan, M.B. Galvanostatic polymerisation of aniline on steel: Improving the coating performance in chloride-containing environment. Synth. Met. 2013, 180, 54-58. [CrossRef]

16. Cascalheira, A.C.; Aeiyach, S.; Lacaze, P.C.; Abrantes, L.M. Electrochemical synthesis and redox behaviour of polypyrrole coatings on copper in salicylate aqueous solution. Electrochim. Acta 2003, 48, 2523-2529. [CrossRef]

17. Sitaram, S.P.; Stoffer, J.O.; Keefe, J.O. Application of Conducting Polymers in Corrosion Protection. J. Coat. Technol. 1997, 866, 65-69. [CrossRef]

18. Malinauskas, A. Chemical deposition of conducting polymers. Polymer 2001, 42, 3957-3972. [CrossRef]

19. Gospodinova, N.; Terlemezyan, L. Conducting polymers prepared by oxidative polymerisation: Polyaniline. Prog. Polym. Sci. 1998, 23, 1443-1484. [CrossRef]

20. Raotole, P.; Patil, P.P.; Gaikwad, A.B. Polypyrrole coatings on low carbon steel from aqueous oxalate solution. Int. J. Emerg. Technol. Adv. Technol. Eng 2013, 11, 68-73.

21. Iroh, J.O.; $\mathrm{Su}, \mathrm{W}$. Corrosion performance of polypyrrole applied to low carbon steel by an electrochemical process. Electrochim. Acta 2000, 46, 15-24. [CrossRef]

22. Pawar, P.; Gaikawad, A.B.; Patil, P.P. Electrochemical synthesis of corrosion protective polyaniline coatings on mild steel from aqueous salicylate medium. Sci. Technol. Adv. Mater. 2006, 7, 732-744. [CrossRef]

23. Cascalheira, A.C.; Viana, A.S.; Abrantes, L.M. In situ atomic force microscopy investigation of copper behaviour and polypyrrole deposition from salicylate medium. Electrochim. Acta 2008, 53, 5783-5788. [CrossRef]

24. Guo, X.W.; Jiang, Y.F.; Zhai, C.Q.; Lu, C.; Ding, W.J. Preparation of even polyaniline film on magnesium alloy by pulse potentiostat method. Synth. Met. 2003, 135-136, 169-170. [CrossRef]

25. Holness, R.J.; Williams, G.; Worsley, D.A.; McMurray, H.N. Polyaniline inhibition of corrosion-driven organic coating cathodic delamination of iron. J. Elecrochem. Soc. 2005, 152, B73-B81. [CrossRef]

26. Gvozdenović, M.M.; Jugović, B.Z.; Stevanović, J.S.; Trišović, T.L.; Grgur, B.N. Electrochemical polymerization of aniline. In Electropolymerization; Schab-Balcerzak, E., Ed.; In Tech: Rijeka, Croatia, 2011; pp. 77-96.

(C) 2017 by the authors. Licensee MDPI, Basel, Switzerland. This article is an open access article distributed under the terms and conditions of the Creative Commons Attribution (CC BY) license (http://creativecommons.org/licenses/by/4.0/). 